\title{
Transgenerational Transmission of Radiation-Induced Expression Patterns of Arabidopsis Thaliana (L.) Heynh. Rad51 and Rad1 Genes
}

\author{
Sergey Litvinov (D)*1, Namik Rashydov (D) 1 \\ ${ }^{1}$ Institute of Cell Biology and Genetic Engineering of the National Academy of Sciences of Ukraine
}

\begin{abstract}
Transcription rates of the genes AtKu70, AtRAD51, AtRad1, involved in maintaining Arabidopsis thaliana genome stability, in relation to the modification of phenotypic characteristics in irradiated plants and their progeny after the action of acute and fractionated X-ray radiation were studied. Differences in the transcription rate were measured by densitometric analysis of cDNA, synthesized by reverse transcription at the template of mRNAs, extracted from fresh leaves after 2 hours irradiation treatment. The doses $3 \mathrm{~Gy}, 12 \mathrm{~Gy}, 15$ Gy and 21 Gy with $1.48 \mathrm{~Gy} / \mathrm{s}$ specific dose rate were applied. Significant correlation between phenotype modifications in $F_{0}$ and $F_{1}$ generations, between phenotype traits and caretaker genes activity in irradiated $\mathrm{F}_{0}$ plants were shown. Also preservation of changes in the pattern of AtRadl and AtRAD51 but not $A t K u 70$ expression in $\mathrm{F}_{1}$ plant leaves had been revealed. Changes in $\mathrm{F}_{1}$ compared with $\mathrm{F}_{0}$ generation do not correspond to the extrapolation of dependence between the phenotypic modifications and DNA repair genes transcription rate in the leaves of irradiated plants. Based on the obtained data it could be suggested that the altered transcriptional activity of AtRAD51 and AtRadl reflects the transfer of DNA lesions from parent to offspring.
\end{abstract}

\section{ARTICLE HISTORY}

Received: 15 January 2018

Revised: 20 February 2018

Accepted: 02 April 2018

\section{KEYWORDS}

Genes expression, $\mathrm{X}$-ray irradiation, DNA repair, Transgenerational inheritance

\section{INTRODUCTION}

Nowadays there is greatly increased interest in the study of the mechanisms of long-term changes in the genome stability of living organisms under the influence of stress factors such as exposure to chemical mutagens, heavy metals, UV, ionizing radiation, adverse extreme climate changes [1-3]. One of the manifestations of such arrangements is to transfer the "memory" of radiation exposure through mitotic and meiotic barrier, what appears on the organism level. Previously, we have identified non-linear wave-like dose-effect dependence for some morphometric characteristics of Arabidopsis thaliana irradiated at the late vegetative stage of development, which characterized by the presence of the "critical points"- sublethal extremums at $3 \mathrm{~Gy}, 12 \mathrm{~Gy}, 15 \mathrm{~Gy}, 21 \mathrm{~Gy}$. Given dependence was more statistically significant in the case of dose fractionation into three equal portions with the time interval between fractions of $24 \mathrm{~h}$. Comparing the dose-effect curves with early changes in transcriptional activity of $A t K u 70$ (NHEJ DNA DSBs repair pathway, telomeric length maintenance and transcriptional silencing [4-7]), AtRAD51 (HR DNA DSBs repair pathway, replication-coupled

CONTACT: Sergey Litvinov $\bigotimes$ slitvinov83@gmail.com $\equiv$ Institute of Cell Biology and Genetic Engineering of the National Academy of Sciences of Ukraine, 148 Acad. Zabolotnogo str., Kiev-03143, Ukraine 
DNA repair, DNA interstrand crosslinks repair, cluster DNA damage repair [5, 7-9], AtRad1 (DNA excision repair, SSA and MMEJ error-prone DNA repair, telomeric length maintenance, DNA interstrand crosslinks repair, cluster DNA damage repair [2, 9-15] genes, that participate in the maintaining of the genomic integrity, a close correlation between the level of activity of these loci and phenotypic features of irradiated plants on the $30^{\text {th }}$ day after irradiation was observed [16]. This means that at least part of long-term effects could be associated with radiation-induced modification of the caretaker genes activity.

\section{MATERIAL AND METHODS}

Experimental methods and research design have been described in [16]. The relative concentration of the AtKu70, AtRAD51, AtRad1 mRNAs in rosette leaves of 35-days-old A. thaliana plants after acute and fractionated whole-plant irradiation with $180 \mathrm{keV} \mathrm{X}$-rays was studied. The exposure specific dose rate was $1.48 \mathrm{~Gy} / \mathrm{s}$ and doses, previously described as sublethal "critical points" [16], were 3 Gy, 12 Gy, 15 Gy and 21 Gy. Experiments had been repeated for three times.

Two generations of plants were used: $F_{0}$ - irradiated on X-ray generator RUM-17 (National Cancer Institute, Kiev, Ukraine) and their non-irradiated progeny $\mathrm{F}_{1}$. cDNAs was synthesized by reverse transcription of mRNAs, extracted from fresh leaves $2 \mathrm{~h}$ after irradiation. Then a PCR amplification of the cDNAs complementary to the mRNAs of the studied genes was performed. Differences in the relative level of expression were measured by densitometric DNA analysis using the ImageJ software package (National Institutes of Health, USA) after agarose gel electrophoresis [17]. The results were normalized to the cDNA concentration of the reference housekeeping gene AtEfla. Statistical processing of data was carried out in MS Excel 2003 (Microsoft Corporation, USA) and SPSS 13.0 (IBM, USA).

\section{RESULTS AND DISCUSSION}

In connection to the previously obtained data, the question has been arisen about the effects that occur in the generation $F_{1}$, grown from the seeds of irradiated $F_{0}$ plants. Such effects, correlated with in $\mathrm{F}_{0}$, revealed for the seeds germination rate, 30-days-old seedlings survival and for the proportion of plants with abnormal habitus, which we have referred as R-phenotype. R-phenotype is "reduced" phenotype, which characterizes by dwarfism, stopping on the vegetative phase of development or poor flowering, sterility, small or twisted rosette leaves of dirty-green/"anthocyanin" color with hypertrophic trichomes [16, 18]. Frequency of plants with the described phenotype also increase in response to other abiotic (drought and cold) and biotic stresses (pathogen invasion or insect attack). We have find that percentage of R-plants in $F_{1}$ closely related to the percentage of $\mathrm{R}$-plants in $\mathrm{F}_{0}$ after acute and fractionated radiation exposure, to the relative frequency of plants exhibiting growth arrest and to the stem growth rate after fractionated irradiation (Figure 1, Table 1). Interestingly, that after fractional X-ray irradiation correlations between a larger number of phenotypic features of irradiated plants and their progeny than after acute irradiation are observed.

Phenotype "inheritance" can realized through the transgenerational transition of DNA lesions, which cause modified phenotype and in parallel activates the transcription of DNA repair genes, or through the transmitting of expression pattern of such genes to the generation of non-irradiated plants. In this case pattern in turn leads to a deviation of the plant phenotype from normal. Both variants assume a stable relationship between the phenotype and the genes activity, as well as the cross-generational correspondence of expression pattern of the studied loci. In full accordance with the assumptions made, our results showed, first, significant correlations of "inherited" radiation-modified group phenotypic traits with AtRad1, AtRAD51 and $A t K u 70$ transcription rates in $\mathrm{F}_{0}$ generation (Table 2, Table 3), second, preservation of 
changes in the pattern of expression of AtRadl and AtRAD51 in leaves of the $\mathrm{F}_{1}$ generation (Figure 2).

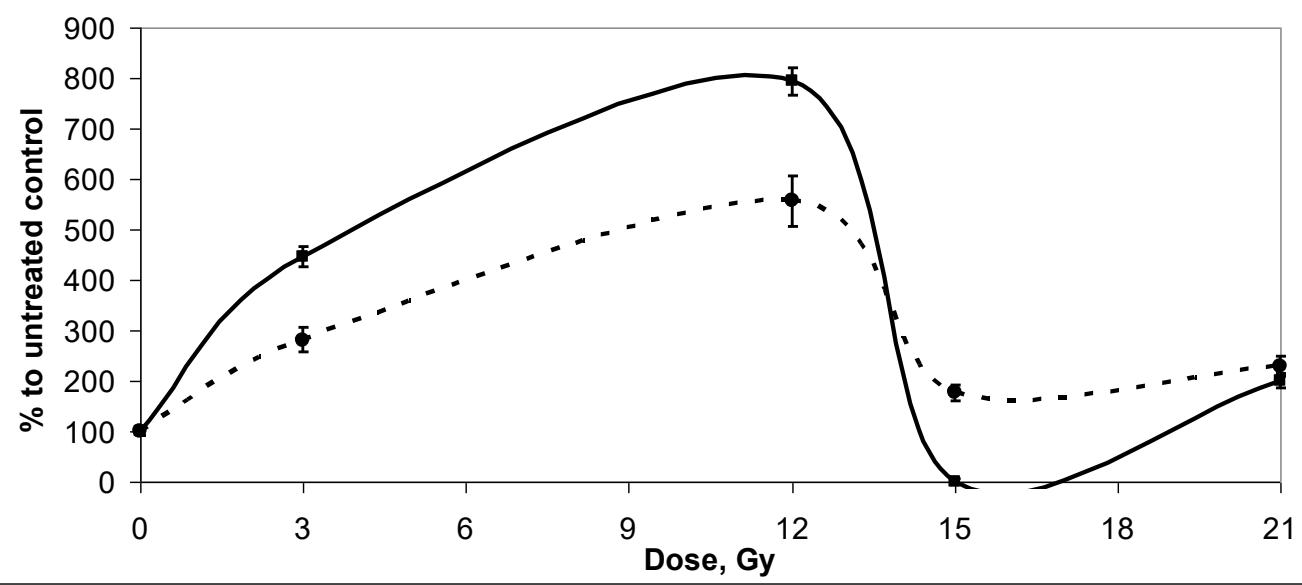

$\rightarrow-$ Relative frequency of plants with R-phenotype (F0)

- • - Relative frequency of plants with R-phenotype (F1)

A. Acute X-irradiation.

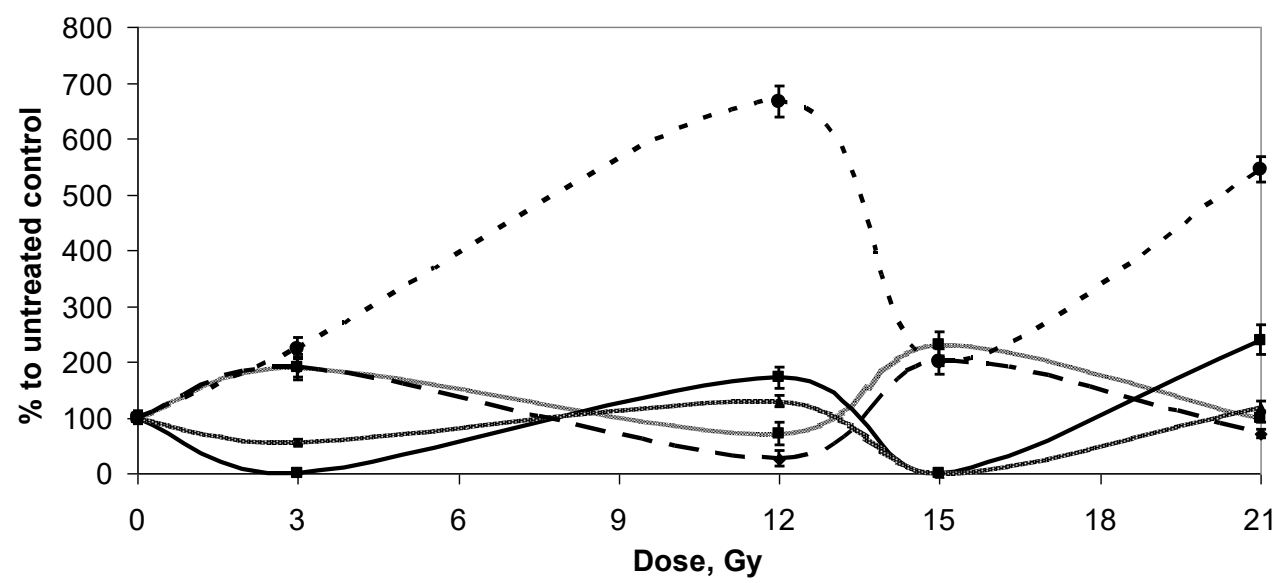

\begin{tabular}{l}
$\longrightarrow$ - Stem growth rate (F0) \\
$\rightarrow-$ Relative frequency of plants with R-phenotype (F0) \\
- - - Relative frequency of plants exhibiting growth arrest after irradiation (F0) \\
\hline
\end{tabular}

\section{B. Fractionated X-irradiation.}

Figure 1. Dose-response curves for some related characteristics of acute (A) and fractional (B) X-ray irradiated $\mathrm{F}_{0}$ and non-irradiated $\mathrm{F}_{1}$ Arabidopsis plants. Every point on the graph represents the average of three experimental repeats with standard error bars. 
Table 1. Pearson's correlation coefficients between related characteristics of irradiated $\mathrm{F}_{0}$ and nonirradiated $\mathrm{F}_{1}$ Arabidopsis plants.

\begin{tabular}{lcc}
\hline & $\begin{array}{c}\text { Relative frequency of plants } \\
\text { with R-phenotype, acute } \\
\text { irradiation }\left(\mathrm{F}_{1}\right)\end{array}$ & $\begin{array}{c}\text { Relative frequency of plants } \\
\text { with R-phenotype, fractionated } \\
\text { irradiation }\left(\mathrm{F}_{1}\right)\end{array}$ \\
\hline $\begin{array}{l}\text { Relative frequency of plants } \\
\text { with R-phenotype, acute } \\
\text { irradiation }\left(\mathrm{F}_{0}\right)\end{array}$ & $0.94^{*}$ & - \\
$\begin{array}{l}\text { Relative frequency of plants } \\
\text { with R-phenotype, fractionated } \\
\text { irradiation }\left(\mathrm{F}_{0}\right)\end{array}$ & - & $0.75^{*}$ \\
$\begin{array}{l}\text { Relative frequency of plants } \\
\text { exhibiting growth arrest after } \\
\text { irradiation, fractionated } \\
\text { irradiation }\left(\mathrm{F}_{0}\right)\end{array}$ & - & $0.64^{*}$ \\
$\begin{array}{l}\text { Stem growth rate, fractionated } \\
\text { irradiation }\left(\mathrm{F}_{0}\right)\end{array}$ & - & $-0.59^{*}$ \\
\hline
\end{tabular}

$* \mathrm{P} \leq 0.05$

Table 2. Pearson's correlation coefficients between radiation-modified group phenotypic characteristics $\left(\mathrm{F}_{0}\right)$ and AtRad1, AtRAD51, AtKu70 transcription rates $\left(\mathrm{F}_{0}\right)$.

\begin{tabular}{llll}
\hline & AtRad1 & AtRAD51 & AtKu70 \\
\hline $\begin{array}{l}\text { Relative frequency of plants with R-phenotype, acute irradiation }\left(\mathrm{F}_{0}\right) \\
\begin{array}{l}\text { Relative frequency of plants with R-phenotype, fractionated } \\
\text { irradiation }\left(\mathrm{F}_{0}\right)\end{array}\end{array}$ & $0,86^{*}$ & & \\
$\begin{array}{l}\text { Relative frequency of plants exhibiting growth arrest after irradiation, } \\
\text { fractionated irradiation }\left(\mathrm{F}_{0}\right)\end{array}$ & $0,76^{*}$ & $-0,79^{*}$ & $-0,62^{*}$ \\
Stem growth rate, fractionated irradiation $\left(\mathrm{F}_{0}\right)$ & $-0,55^{*}$ & $-0,86^{*}$ \\
\hline
\end{tabular}

$* \mathrm{P} \leq 0.05, * * \mathrm{P} \leq 0.01$

Table 3. Pearson's correlation coefficients between radiation-modified group phenotypic characteristics $\left(\mathrm{F}_{1}\right)$ and AtRad1, AtRAD51, AtKu70 transcription rates $\left(\mathrm{F}_{0}\right.$ and $\left.\mathrm{F}_{1}\right)$.

\begin{tabular}{lcccccc}
\hline & AtRad1 & AtRAD51 & AtKu70 & AtRadl & AtRAD51 & AtKu70 \\
& $\left(\mathrm{F}_{0}\right)$ & $\left(\mathrm{F}_{0}\right)$ & $\left(\mathrm{F}_{0}\right)$ & $\left(\mathrm{F}_{1}\right)$ & $\left(\mathrm{F}_{1}\right)$ & $\left(\mathrm{F}_{1}\right)$ \\
\hline $\begin{array}{l}\text { Relative frequency of plants with } \mathrm{R}- \\
\text { phenotype, acute irradiation }\left(\mathrm{F}_{1}\right)\end{array}$ & $0,72^{*}$ & & & $0,97 * *$ & \\
$\begin{array}{l}\text { Relative frequency of plants with } \mathrm{R}- \\
\text { phenotype, fractionated irradiation }\left(\mathrm{F}_{1}\right)\end{array}$ & & & & & $0,93^{*}$ \\
$\begin{array}{l}\text { Germination rate of the } \mathrm{F}_{0} \text { seeds }+30- \\
\text { days survival rate of seedlings, acute } \\
\text { irradiation }\left(\mathrm{F}_{1}\right)\end{array}$ & & $0,90^{*}$ & & & \\
$\begin{array}{l}\text { Germination rate of the } \mathrm{F}_{0} \text { seeds }+30- \\
\text { days survival rate of seedlings, } \\
\text { fractionated irradiation }\left(\mathrm{F}_{1}\right)\end{array}$ & $-0,75^{*}$ & $0,92^{*}$ & & $-0,64^{*}$ & $0,93^{*}$ \\
$* \mathrm{P} \leq 0.05, * * \mathrm{P} \leq 0.01$ & & & & & & \\
\hline
\end{tabular}




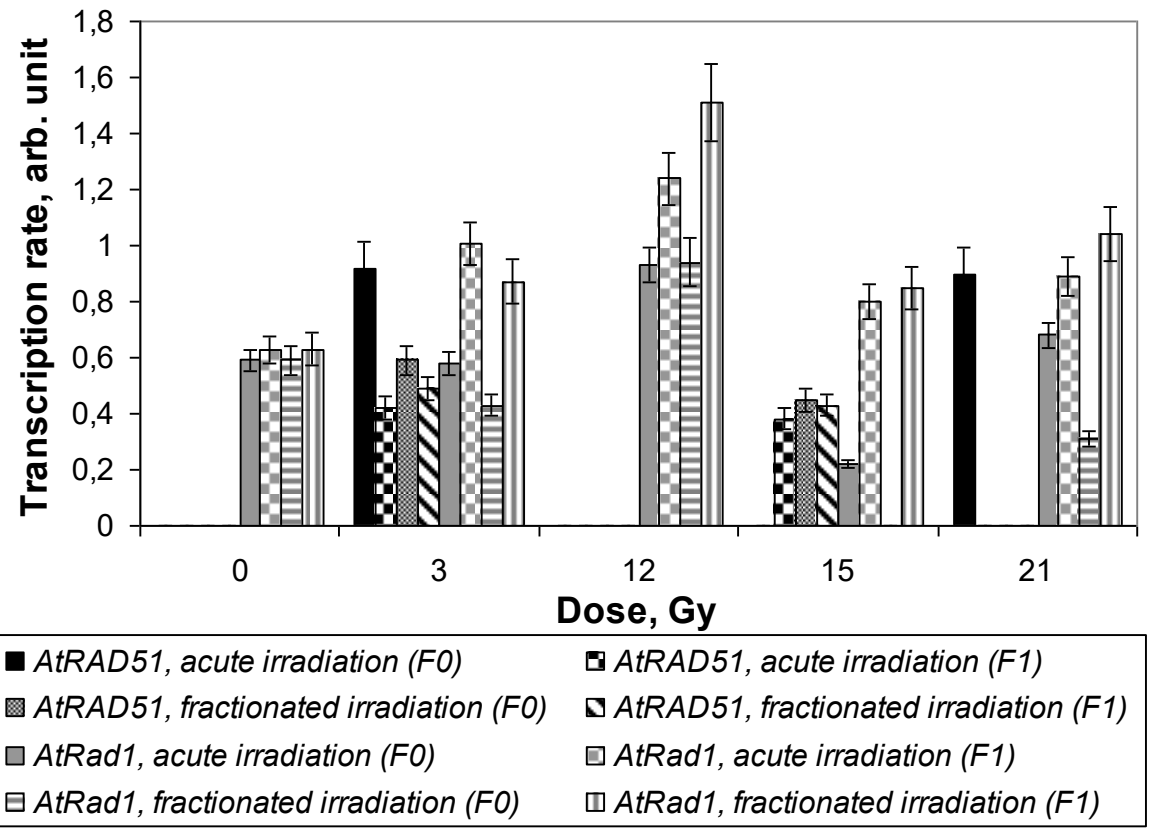

Figure 2. Relative transcription rate of AtRAD51 and AtRad1 genes in rosette leaves of A. thaliana plants of irradiated $F_{0}$ and non-irradiated $F_{1}$ generations. Each bar in a diagram represents the average of three repeated experimental measurements, normalized to the AtEfla reference transcription activity in leaves of non-irradiated plants with standard error bars.

There were no changes in transcription rate of AtKu70 in progeny of irradiated plants in comparison with progeny of control plants. At all tested doses and irradiation modes, the level of expression of AtRad1 was higher in rosette leaves of non-irradiated plants of the $\mathrm{F}_{1}$ generation versus irradiated plants of the $\mathrm{F}_{0}$ generation (Figure 2). As for the marker gene of double-strand DNA breaks of AtRAD51, the main factor of homologous recombination, its expression in the progeny increases only after acute irradiation of the parental plants at a dose $15 \mathrm{~Gy}$. This is the solely dose of acute irradiation, at which the relative frequency of R-plants increases in $F_{1}$ (Figure 1(A)). With fractionated irradiation, given index in $F_{1}$ is higher than in F0 at all doses used (Figure 1(B)). Thereby, changes in $\mathrm{F}_{1}$ in comparison with $\mathrm{F}_{0}$ generation do not correspond to the extrapolation of the relationship between the phenotype and the level of caretaker genes expression in the leaves of irradiated plants. This indirectly confirms the second of the above-mentioned inheritance mechanisms for the radiation-modified phenotype, transgenerational transition of unrepaired DNA lesions (probably single-stranded lesions, which is indicated by an increase in the transcriptional activity of AtRadl but not AtRAD51 and $A t K u 70$ ), so that DNA repair genes are induced in the leaves of the non-irradiated progeny by the transmitted parental DNA damages.

\section{CONCLUSION}

Based on discussed data could draw conclusion, that radiation-induced changes in plants can be transmitted to the next generation. The transgenerational transmission of modified transcriptional rates of key DNA repair genes correlates with phenotypic effects in the nonirradiated offspring of the irradiated plants. Dose fractionation with $24 \mathrm{~h}$ time interval cause correlation between a larger number of phenotypic features of irradiated plants and their progeny than after acute irradiation. It is unclear whether this is a manifestation of the hypothetical inheritance of the altered transcriptional activity or reflects the transfer of DNA lesions from parent to offspring via gametogenic cell line. But there are indirect evidences in favor of the second possibility meaning transgenerational transmission of the unrepaired ssDNA lesions. 
In general, these results shed light on the fundamental biological problem of inheritance of acquired characteristics under influence adverse stress factors.

\section{Acknowledgements}

This work was supported by the European Union's 7th Framework Program FP7-PEOPLE2013-IRSES - Marie Curie Action "International Research Staff Exchange Scheme", IRSESGA-2013-612587 "Plant DNA tolerance. Plant adaptation to heavy metal and radioactive pollution".

Orcid

Sergey Litvinov (D) https://orcid.org/0000-0002-9185-4807

Namik Rashydov (iD https://orcid.org/0000-0001-5387-4877

\section{REFERENCES}

[1] Mannuss, A., Trapp, O., Puchta, H. (2012). Gene Regulation in Response to DNA Damage, Biochimica et Biophysica Acta, 1819(2), 154-165.

http://dx.doi.org/10.1016/j.bbagrm.2011.08.003

[2] Vannier, J.-B., Depeiges, A., White, C., Gallego, M.E. (2009). ERCC1/XPF Protects Short Telomeres from Homologous Recombination in Arabidopsis thaliana, PLOS Genetics, 5(2), e1000380. http://dx.doi.org/10.1371/journal.pgen.1000380

[3] Yoshiyama, K., Sakaguchi, K., Kimura, S. (2013). DNA Damage Response in Plants: Conserved and Variable Response Compared to Animals, Biology, 2 (4), 1338-1356. http://dx.doi.org/10.3390/biology2041338

[4] Boulton, S., Jackson, S. (1998) Components of the Ku-dependent non-homologous endjoining pathway are involved in telomeric length maintenance and telomeric silencing, The EMBO Journal, 17(6), 1819-1828. http://dx.doi.org/10.1093/emboj/17.6.1819

[5] Frankenberg-Schwager, M., Gebauer, A., Koppe, C., Wolf, H., Pralle, E., Frankenberg, D. (2009). Single-strand annealing, conservative homologous recombination, nonhomologous DNA end joining, and the cell cycle-dependent repair of DNA double-strand breaks induced by sparsely or densely ionizing radiation, Radiation Research, 171(3), 265-273. http://dx.doi.org/10.1667/RR0784.1

[6] Lieber, M.R. (2010). NHEJ and Its Backup Pathways: Relation to Chromosomal Translocations, Nature Structural \& Molecular Biology, 17(4), 393-395. http://dx.doi.org/10.1038/nsmb0410-393

[7] Waterworth, W., Drury, G., Bray, C., West, C. (2011). Repairing Breaks in the Plant Genome: The Importance of Keeping It Together, New Phytologist, 192 (4), 805-822. http://dx.doi.org/10.1111/j.1469-8137.2011.03926.x

[8] Li, J., Harper, L.C., Golubovskaya, I., Wang, C.R., Weber, D., Meeley, R.B., McElver, J., Bowen, B., Cande, W.Z., Schnable, P.S. (2007). Functional Analysis of Maize RAD51 in Meiosis and Double-Strand Break Repair, Genetics, 176(3), 1469-1482. http://dx.doi.org/10.1534/genetics.106.062604

[9] Ma, W., Westmoreland J. W., Resnick M. A. (2013). Homologous recombination rescues ssDNA gaps generated by nucleotide excision repair and reduced translesion DNA synthesis in yeast G2 cells, PNAS, 110(31), 2895-2904. http://dx.doi.org/10.1073/pnas.1301676110

[10] Besse, B., Olaussen, K.A., Soria, J.C. (2013). ERCC1 and RRM1: ready for prime time?, Journal of Clinical Oncology, 31(8), 1050-1060.

http://dx.doi.org/10.1200/JCO.2012.43.0900 
[11]Hwang, J.-Y., Smith, S., \& Myung, K. (2005). The Rad1-Rad10 Complex Promotes the Production of Gross Chromosomal Rearrangements from Spontaneous DNA Damage in Saccharomyces cerevisiae, Genetics, 169(4), 1927-1937.

http://dx.doi.org/10.1534/genetics.104.039768

[12] Ma, J.L., Kim, E.M., Haber, J.E., Lee, S.E. (2003). Yeast Mre11 and Rad1 proteins define a $\mathrm{Ku}$-independent mechanism to repair double-strand breaks lacking overlapping end sequences, Molecular and Cellular Biology, 23(23), 8820-8828. http://dx.doi.org/10.1128/MCB.23.23.8820-8828.2003

[13] McVey, M., Lee, S.E. (2008). MMEJ repair of double-strand breaks (director's cut): deleted sequences and alternative endings, Trends in Genetics, 24(11), 529-538. http://dx.doi.org/10.1016/j.tig.2008.08.007

[14] Scuric, Z., Chan, C.Y., Hafer, K., Schiestl, R.H. (2009). Ionizing Radiation Induces Microhomology-Mediated End Joining in trans in Yeast and Mammalian Cells, Radiation Research, 171(4), 454-463. http://dx.doi.org/10.1667/RR1329.1

[15] Zhang, Y., Rohde, L.H., Wu, H. (2009). Involvement of nucleotide excision and mismatch repair mechanisms in double strand break repair, Current Genomics, 10(4), 250-258. http://dx.doi.org/10.2174/138920209788488544

[16] Litvinov, S., Rashydov, N. (2017) The transcriptional response of Arabidopsis thaliana L. AtKu70, AtRAD51 and AtRadl genes to X-rays, Journal of Agricultural Science and Technology A, 7 (1), 52-60. http://dx.doi.org/10.17265/2161-6256/2017.01.008

[17] Bradford, W., Cahoon, L., Freel, S., Mays Hoopes, L., Eckdahl, T. (2005) An Inexpensive Gel Electrophoresis-Based Polymerase Chain Reaction Method for Quantifying mRNA Levels, Cell Biology Education, 4(2), 157-168. http://dx.doi.org/10.1187/cbe.04-09-0051

[18] Litvinov, S. (2014). Effects of Chronic Exposure of Seeds and Seedlings of Arabidopsis thaliana by Low Doses of $\gamma$-Radiation on Plant Growth and Development, Nuclear Physics and Atomic Energy, 15(4), 406-414. 